\title{
Pertumbuhan dan Hasil Kedelai, Respon terhadap Pupuk Hayati di Lahan Sawah Kabupaten Pandeglang, Banten
}

\author{
(Growth and Yield of Soybean, Response to Biofertilizer in Paddy Field Pandeglang, Banten) \\ Yati Astuti $^{1 *}$, Resmayeti Purba ${ }^{1}$ \\ ${ }^{1}$ Balai Pengkajian Teknologi Pertanian Banten, \\ Jl.Raya Ciptayasa Km 01 Ciruas, Serang, Banten Kode Pos 42182 \\ Telp. (0254) 281055; Fax (0254) 282507 HP. 087772539191 \\ Email: yutia_84@yahoo.com
}

Diterima 21 Desember 2016/Disetujui 14 Januari 2017

\begin{abstract}
The purpose of this study is to determine the effectiveness of biofertilizer on growth and yield of soybean. The experiment was conducted at the paddy field Mekarsari village, Panimbang Subdistrict, Pandeglang District, Banten Province from Agustus to Oktober 2016. The experimental was laid out in randomized block design single factor with five treatments and six replications. The treatments were (A). Without fertilization (control); (B). Recommended fertilizer $\left(25 \mathrm{~kg} \mathrm{ha}^{-1}\right.$ of urea $+100 \mathrm{~kg} \mathrm{ha}-1 \mathrm{SP}-36+100$ $\mathrm{kg} \mathrm{ha}^{-1}$ NPK Phonska), (C) Agrimeth biofertilizer $200 \mathrm{~g} \mathrm{ha}^{-1}+$ recommended fertilizer, (D) Agrimeth biofertilizer $200 \mathrm{~g}$ ha ${ }^{-1}+$ Gliocompost biofertilizer $20 \mathrm{~kg} \mathrm{ha}^{-1}+$ recommended fertilizer, (E) Gliocompost biofertilizer $20 \mathrm{~kg} \mathrm{ha}^{-1}+$ recommended fertilizer. The observed parameters were plant height, leaves number, root length, number of root nodules, number of flower, number of filled pods, and grain yield. Data were analyzed by ANOVA 0.05 continued by DMRT 0.05 if among the treatments significant. The result of research showed that Agrimeth $200 \mathrm{~g} \mathrm{ha}^{-1}+$ Gliocompost $20 \mathrm{~kg} \mathrm{ha}^{-1}+$ recommended fertilizer significantly affect to plant growth, ie plant height, leaves number, number of root nodules, number of flower, number of filled pods and soybean yields.

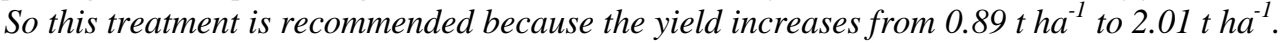

Keywords: Agrimeth, biofertilizer, Gliocompost, paddy field, soybean

ABSTRAK

Penelitian bertujuan untuk mempelajari efektifitas pupuk hayati terhadap pertumbuhan dan hasil kedelai. Penelitian dilaksanakan di lahan sawah desa Mekarsari Kec. Panimbang, Kabupaten Pandeglang, Banten dari bulan Agutus hingga Oktober 2016. Percobaan menggunakan rancangan acak kelompok faktor tunggal dengan lima perlakuan dan enam ulangan. Perlakuan adalah (A). Tanpa pemupukan (kontrol); (B). Pupuk rekomendasi: $25 \mathrm{~kg} \mathrm{ha}^{-1}$ Urea $+100 \mathrm{~kg} \mathrm{ha}^{-1} \mathrm{SP}-36+100 \mathrm{~kg} \mathrm{ha} \mathrm{NPK}^{-1}$ Phonska, (C) pupuk hayati Agrimeth 200 gram ha ${ }^{-1}+$ pupuk rekomendasi (D). pupuk hayati Agrimeth 200 gram ha ${ }^{-1}+$ Gliocompost $20 \mathrm{~kg} \mathrm{ha}^{-1}+$ pupuk rekomendasi (E) pupuk hayati Gliocompost $20 \mathrm{~kg} \mathrm{ha}^{-1}+$ pupuk rekomendasi. Parameter pengamatan adalah tinggi tanaman, jumlah daun, panjang akar, jumlah bintil akar, jumlah bunga, jumlah polong isi, dan hasil biji kedelai. Data pengamatan dianalisis menggunakan Analysis of Varians (ANOVA) 0,05. Uji lanjut menggunakan Duncan Multiple Range Test (DMRT) 0,05 jika antar perlakuan berbeda nyata. Hasil penelitian menunjukkan bahwa pupuk hayati Agrimeth $200 \mathrm{~g} \mathrm{ha}^{-1}+$ pupuk hayati Gliocompost $20 \mathrm{~kg} \mathrm{ha}^{-1}+$ pupuk rekomendasi berpengaruh nyata terhadap pertumbuhan tanaman, yaitu tinggi tanaman, jumlah daun, jumlah bintil akar, jumlah bunga, jumlah polong isi, dan hasil kedelai. Pupuk tersebut sebagai rekomendasi karena meningkatkan hasil kedelai dari 0,89 t ha ${ }^{-1}$ (kontrol) menjadi 2,01 t ha ${ }^{-1}$.

Kata Kunci: Agrimeth, Gliocompost, kedelai, lahan sawah, pupuk hayati

\section{PENDAHULUAN}

Budidaya kedelai di lahan sawah petani menunjukkan bahwa tingkat produktivitas berkisar $0,8-1,2 \mathrm{t} \mathrm{ha}^{-1}$, menggunakan pupuk Urea $25-50 \mathrm{~kg} \mathrm{ha}^{-1}$, SP-36 50-100 kg $\mathrm{ha}^{-1}$ dan NPK Phonska 50-100 kg ha ${ }^{-1}$, tanpa bahan organik. Sedangkan produktivitas kedelai ditingkat penelitian saat ini berkisar 1,5-2,5 $\mathrm{t} \mathrm{ha}^{-1}$ dengan pemupukan rekomendasi umum: 
Urea 100-150 kg ha-1 Sp-36 50-100 kg ha-1, KCl 50-100 kg $\mathrm{ha}^{-1}$ dan bahan organik 1-2 $\mathrm{tha}^{-1}$. Kesenjangan hasil antara petani dengan penelitian antara lain disebabkan oleh tanah di lahan sawah kekurangan bahan organik. Kondisi ini menyebabkan struktur tanah tidak dapat mendukung perkembangan akar dalam penyerapan unsur hara dan unsur hara tidak tersedia bagi tanaman kedelai. Akibatnya, pemupukan yang dilakukan petani tidak efisien karena unsur hara tidak diserap tanaman. Upaya memperbaki kualitas tanah dapat diberikan pupuk hayati sebagai pembenah tanah. Pupuk hayati memiliki keunggulan yaitu: meningkatkan keanekaragaman dan aktivitas populasi mikroba tanah, memperbaiki struktur tanah, sebagai sumber hara, meningkatkan hasil tanaman, meningkatkan serapan hara oleh tanaman (Saraswati 2000; Suhartatik dan Sismiyati 2000; Sasli 2013). Penggunaan pupuk hayati pada kedelai bermanfaat memperbaiki kualitas tanah dan meningkatkan kandungan bahan organik (Saraswati 2013; Harsono et al., 2012; Harsono et al., 2013). Pemanfaatan pembenah tanah pupuk hayati pada budidaya kedelai merupakan upaya memperbaiki struktur fisik dan bilogi tanah sehingga akar tanaman dapat menyerap unsur hara lebih baik, yang akhirnya berdampak kepada pertumbuhan tinggi tanaman, jumlah daun, panjang akar, jumlah polong isi dan hasil biji kedelai. Keefektifan pupuk hayati dalam meningkatkan hasil kedelai telah dilaporkan beberapa peneliti. Pupuk hayati Iletrisoy-2 dan Rhizogin dapat meningkatkan hasil dari 1,10 menjadi $1,94 \mathrm{t} \mathrm{ha}^{-1}$; penggunaan Ileytrisoy- $2+$ Santap $1,5 \mathrm{t} \mathrm{ha}^{-1}$ meningkatkan hasil kedelai dari 1,10 menjadi $1,82 \mathrm{t} \mathrm{ha}^{-1}$ (Harsono et al., 2012; Harsono et al., 2013).

Balai Penelitian Tanah (2015) melaporkan bahwa komposisi Agrimeth: (a) Azotobacter vinelandii (penambat $\mathrm{N} 2$, non simbiotik dan pelarut $\mathrm{P}$ tanah), (b). Bacillus cereus (pelarut $\mathrm{P}$ tanah, penghasil senyawa anti patogen), (c). Bradyrhizobium sp dan Rhizobium sp (penambat N2 simbiotik), (d). Methlyobactterium sp (penghasil fitohormon). Selanjutnya Balai Penelitian Tanaman Hias (2015) melaporkan bahwa komposisi Gliocompost adalah Azospirillium sp., yang mempunyai keunggulan sebagai penyedia $\mathrm{N}$ dan $\mathrm{P}$ secara alamiah, pembenah tanah, memperbaiki kualitas tanah dan membantu penyerapan unsur hara serta dan menjaga kesehatan tanaman. Berdasarkan keunggulan pupuk hayati tersebut maka dilakukan penelitian untuk mempelajari efektivitas pemanfaatan Agrimeth dan Gliocompost terhadap pertumbuhan dan hasil kedelai di lahan sawah, Kabupaten Pandeglang, Banten.

\section{BAHAN DAN METODE}

Penelitian berupa percobaan dilaksanakan pada bulan Agustus-Oktober 2016 di Desa Mekarsari, Kecamatan Panimbang, Kabupaten Pandeglang, Banten. Bahan yang digunakan adalah benih kedelai varietas Gema, Urea, SP-36, NPK Phonska, pupuk hayati Agrimeth, pupuk hayati Gliocompost. Alat yang digunakan adalah cangkul, timbangan, bambu, papan nama, arit, meteran, buku dan alat tulis.

Percobaan menggunakan Rancangan Acak Kelompok (RAK) faktor tunggal dengan lima taraf perlakuan dan enam ulangan. Perlakuan terdiri atas A: Tanpa pemupukan (Kontrol), B: Pupuk rekomendasi (Urea $25 \mathrm{~kg} \mathrm{ha}^{-1}+$ SP-36 $100 \mathrm{~kg} \mathrm{ha}^{-1}+100 \mathrm{~kg}$ NPK Phonska), C: Agrimeth $200 \mathrm{~g} \mathrm{ha}^{-1}($ Agri) + pupuk rekomendasi, D: Agrimeth $200 \mathrm{~g} \mathrm{ha}^{-1}$ (Agri) + Gliocompost $20 \mathrm{~kg} \mathrm{ha}^{-1}$ (Glio)+ pupuk rekomendasi, E: Gliocompost $20 \mathrm{~kg} \mathrm{ha}^{-1}$ (Glio) + pupuk rekomendasi.

Ukuran petak percobaan $20 \times 8 \mathrm{~m}$ berjumlah 30 petak di lahan tanpa olah. Benih kedelai varietas Gema ditanam 2 biji per lubang dengan jarak tanam $40 \times 20 \mathrm{~cm}$. Aplikasi pupuk hayati Agrimeth dan Gliocompost dilakukan sesuai dengan petunjuk penggunaan yang telah ditentukan oleh Balittanah dan Balithi. Penggunaan Agrimeth: benih kedelai dibasahi sampai cukup basah, ditiriskan, kemudian dicampur rata dengan Agrimeth (200 $\left.\mathrm{g} \mathrm{ha}^{-1}\right)$, selanjutnya segera ditanam dan sisanya dibenamkan di lubang tanam. Gliocompost sebagai penutup lubang tanam pada saat tanam kedelai dengan dosis $20 \mathrm{~kg} \mathrm{ha}^{-1}$. Dosis pupuk anorganik Urea, SP-36 dan NPK Phonska masing-masing 25, 100, dan $100 \mathrm{~kg} \mathrm{ha}^{-1}$. Pupuk Urea, Phonska dan SP-36 diberikan saat tanaman kedelai umur 14 hari. Pemupukan dengan cara memasukkan pupuk pada lubang dibuat dengan tugal di samping barisan tanaman berjarak sekitar $5 \mathrm{~cm}$ dari tanaman. Penyiangan dilakukan pada umur 30 dan 60 hari. Panen dilakukan pada umur 72-75 hari sesuai deskripsi varietas Gema (Balitkabi, 2013).

Parameter yang diamati adalah tinggi tanaman $(\mathrm{cm})$, jumlah daun (lembar), panjang akar (cm), jumlah bintil akar, jumlah bunga, jumlah polong isi, hasil biji per hektar $\left(\mathrm{t} \mathrm{ha}{ }^{-1}\right)$. Pengamatan tinggi tanaman dilakukan pada 10 tanaman contoh per petak perlakuan pada umur 15, 30, 42, 63 hari dan saat panen. Jumlah daun dihitung pada umur 15, 30 dan 42 hari. Pengamatan= panjang akar, bintil akar dan jumlah bunga dilakukan pada umur 42 hari dengan mengambil 10 tanaman per petak perlakuan. Penghitungan jumlah polong pada saat panen, dilakukan dengan mengambil 25 rumpun tanaman dari setiap petak perlakuan. Hasil biji kedelai diukur pada saat panen dengan melakukan ubinan berukuran 4 × 5 m pada setiap petak perlakuan. Hasil ubinan setiap perlakuan dikonversikan ke satuan hektar. Data hasil pengamatan dianalisi menggunakan Analysis of Varians (ANOVA) 0,05. Perlakuan yang berbeda nyata diuji lanjut menggunakan uji Duncan Multiple Range Test (DMRT) pada taraf ( $\alpha$ ) 0,05.

\section{HASIL DAN PEMBAHASAN}

Pola pertumbuhan kedelai sebagai respon terhadap pemupukan tampak agak berbeda, menggunakan pupuk rekomendasi, agri dan rekomendasi, glio dan rekomendasi setelah tanaman umur 42 hari laju pertumbuhan kemudian konstan. Tanpa pemupukan setelah umur 42 hari laju pertumbuhan turun, sedangkan menggunakan pupuk agri, glio dan rekomendasi, setelah umur 42 hari laju pertumbuhan 
meningkat (Gambar 1). Ini berarti pemupukan menggunakan pupuk agri, glio dan rekomendasi memberikan pertumbuhan tinggi tanaman yang paling baik dibanding pemupukan yang lain. Demikian pula pada jumlah daun, memiliki pola yang sama dengan pertumbuhan tinggi tanaman.

Pola pertumbuhan jumlah daun kedelai sebagai respon terhadap pemupukan tampak agak berbeda, menggunakan pupuk rekomendasi, agri dan rekomendasi, glio dan rekomendasi setelah tanaman umur 42 hari laju pertumbuhan kemudian konstan. Tanpa pemupukan setelah umur 42 hari laju pertumbuhan turun, sedangkan menggunakan pupuk agri, glio dan rekomendasi, seteah umur 42 hari laju pertumbuhan meningkat (Gambar 2). Ini berarti pertumbuhan dengan menggunakan pupuk agri, glio dan rekomendasi memberikan pertumbuhan jumlah daun yang paling baik dibanding pemupukan yang lain.

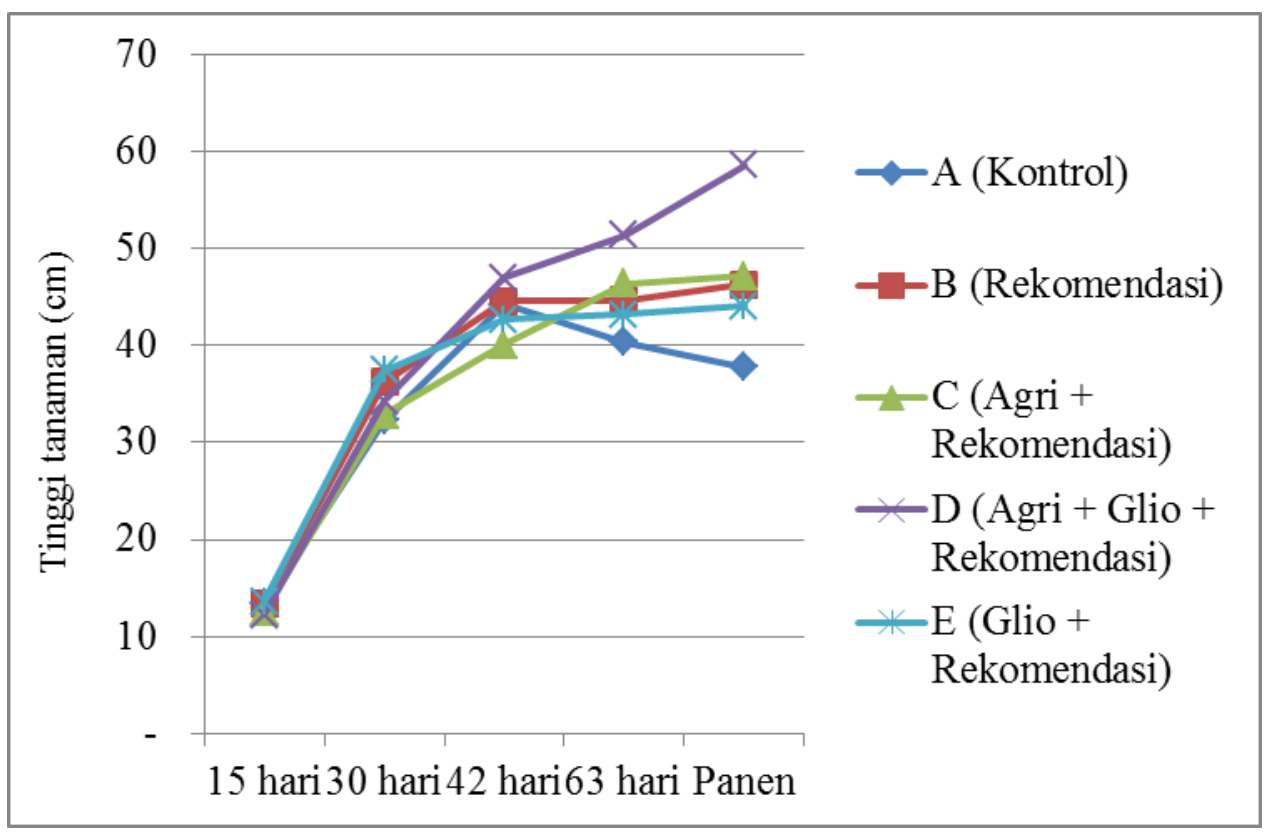

Gambar 1. Tinggi tanaman kedelai pada berbagai perlakuan pemupukan

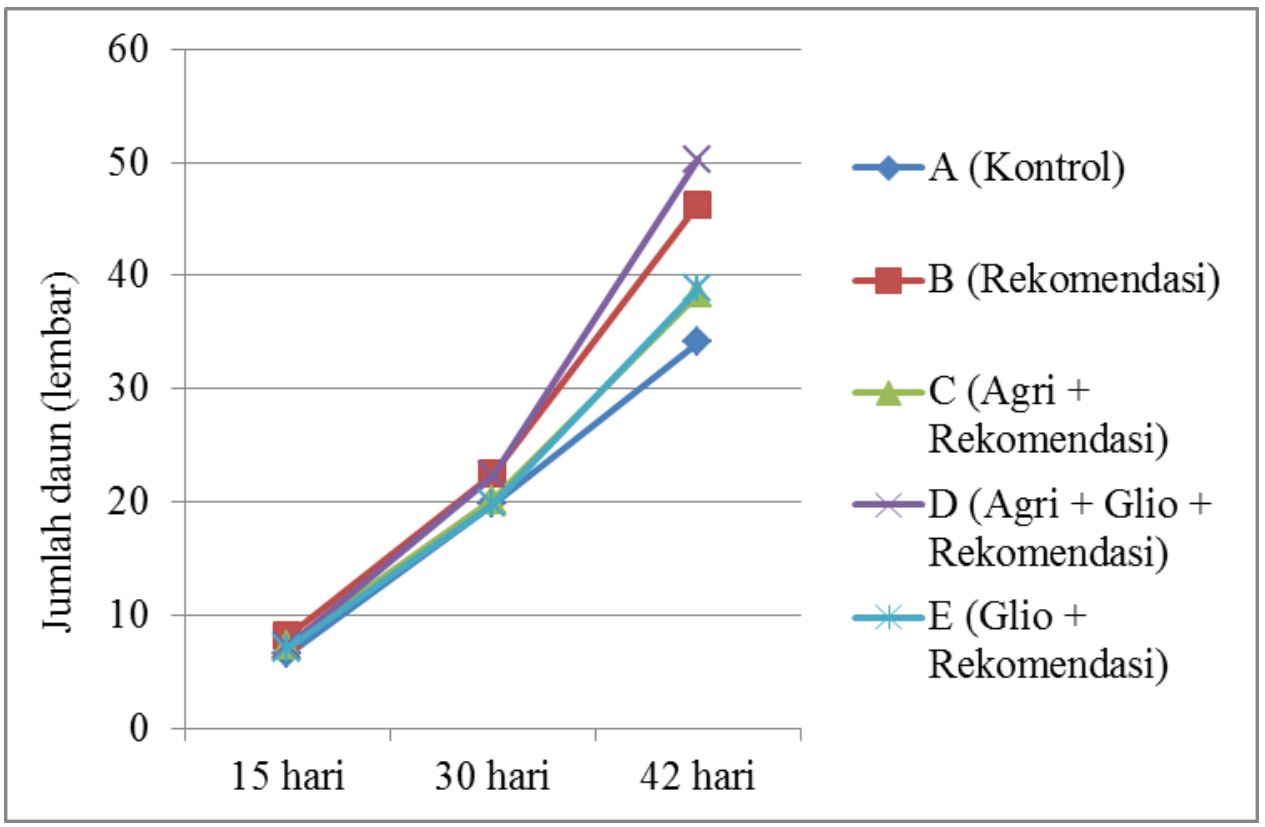

Pertumbuhan dan Hasil Kedelai, Respon terhadapPupuk Hayati di Lahan Sawah... 
Gambar 2. Jumlah daun kedelai pada berbagai perlakuan pemupukan

Tabel 1. Pengaruh pemupukan terhadap tinggi tanaman, jumlah daun, panjang akar dan jumlah bintil akar dan jumlah bunga pada berbagai perlakuan

\begin{tabular}{llllll}
\hline Perlakuan & $\begin{array}{l}\text { Tinggi tanaman } \\
\text { saat panen }(\mathrm{cm})\end{array}$ & $\begin{array}{l}\text { Jumlah daun } \\
\text { umur 42 hari }\end{array}$ & $\begin{array}{l}\text { Panjang akar umur } \\
42 \text { hari }(\mathrm{cm})\end{array}$ & $\begin{array}{l}\text { Jumlah bintil akar } \\
\text { umur 42 hari }\end{array}$ & Jumlah bunga umur 42 hari \\
\hline A & $37,73 \mathrm{c}$ & $34,13 \mathrm{c}$ & $10,49 \mathrm{a}$ & $1,80 \mathrm{~b}$ & $37,50 \mathrm{~b}$ \\
$\mathrm{~B}$ & $46,25 \mathrm{~b}$ & $46,27 \mathrm{ab}$ & $10,52 \mathrm{a}$ & $2,60 \mathrm{~b}$ & $11,80 \mathrm{c}$ \\
$\mathrm{C}$ & $47,13 \mathrm{~b}$ & $38,40 \mathrm{bc}$ & $11,99 \mathrm{a}$ & $1,40 \mathrm{~b}$ & $8,07 \mathrm{c}$ \\
$\mathrm{D}$ & $58,57 \mathrm{a}$ & $50,27 \mathrm{a}$ & $13,11 \mathrm{a}$ & $7,10 \mathrm{a}$ & $42,53 \mathrm{a}$ \\
$\mathrm{E}$ & $44,05 \mathrm{~b}$ & $38,87 \mathrm{bc}$ & $12,39 \mathrm{a}$ & $2,50 \mathrm{~b}$ & $12,13 \mathrm{c}$ \\
\hline
\end{tabular}

Keterangan: Angka yang diikuti huruf yang sama pada kolom yang sama tidak berbeda nyata berdasarkan Duncan Multiple Range Test (DMRT) pada taraf $(\alpha) 0,05$.

Tabel 2. Jumlah polong isi dan hasil biji kedelai pada berbagai perlakuan

\begin{tabular}{lll}
\hline Perlakuan & Jumlah polong isi & Hasil biji kedelai $\left(\mathrm{t} \mathrm{ha}^{-1}\right)$ \\
\hline A & $33,17 \mathrm{~d}$ & $0,63 \mathrm{~d}$ \\
B & $37,50 \mathrm{c}$ & $0,88 \mathrm{c}$ \\
C & $39,67 \mathrm{bc}$ & $1,52 \mathrm{~b}$ \\
D & $50,17 \mathrm{a}$ & $2,01 \mathrm{a}$ \\
E & $40,50 \mathrm{~b}$ & $1,66 \mathrm{~b}$ \\
\hline
\end{tabular}

Keterangan: Angka yang diikuti huruf yang sama pada kolom yang sama tidak berbeda nyata berdasarkan Duncan Multiple Range Test (DMRT) pada taraf nyata $(\alpha) 0,05$.

Tanaman dipupuk Agri, Glio berakibat pada tinggi tanaman, jumlah daun, jumlah bintil akar dan jumlah bunga tanaman kedelai berbeda nyata, sedangkan pada panjang akar tidak berbeda nyata (Tabel 1). Jumlah bintil akar terbanyak dihasilkan pada pemupukan Agri, Glio, dan pupuk rekomendasi. Efektivitas pupuk hayati Agri dan Glio pada penelitian nampak pada pertumbuhan bintil akar yang lebih baik, yang menyebabkan kemampuan akar untuk menyerap air dan mengikat unsur hara $\mathrm{N}, \mathrm{P}$ dan $\mathrm{K}$ melalui kaloid tanah meningkat untuk mendukung pertumbuhan dan perkembangan tanaman. Unsur $\mathrm{N}$ diperlukan tanaman kedelai sebagai starter pada awal pertumbuhan, terutama bila kondisi lahan seperti kekeringan, lahan terlalu basah, tanah terlalu padat tidak kondusif bagi pertumbuhan bintil akar tidak baik maka serapan P dan K rendah (Mashuri, 2010).

Tanaman kedelai yang mempunyai bintil akar efektif akan mengandung cukup $\mathrm{N}$ tanah melalui fiksasi $\mathrm{N} 2$ dari atmosfer, ketersediaan hara meningkat, uptake unsur hara meningkat, takaran pupuk berkurang, efisiensi pemupukan meningkat serta tanaman akan tumbuh lebih baik (Soedarjo, 2013). Selanjutnya Saraswati (2000) melaporkan bahwa manfaat dari penggunaan pupuk hayati adalah menyediakan sumber hara bagi tanaman, menstimulir perakaran agar berkembang sempurna. Suhartatik dan Sismiyati (2000) melaporkan hasil penelitian bahwa mikroba yang terdapat di dalam pupuk hayati mampu melarutkan unsur hara dan menyerap unsur hara.

Pemupukan Agri, Glio dan rekomendasi memberikan jumlah polong isi kedelai per tanaman lebih banyak dibanding perlakuan lainnya (Tabel 2). Pemupukan Agri, Glio dan rekomendasi mampu meningkatkan jumlah polong isi per tanaman. Jumlah polong isi merupakan salah satu karakter yang berperan penting terhadap hasil biji kedelai (Sumarsono dan Zuraida. 2006; Sutoro et al., 2008; Hakim, 2012). Pada penelitian ini, nampak efektivitas pemanfaatan Agri, Glio, dan rekomendasi pada hasil biji kedelai lebih tinggi dibanding penggunaan pupuk hayati Agri dan Glio secara terpisah maupun dengan pemberian pupuk rekomendasi dan tanpa pemupukan (Tabel 2). Efektivitas pemanfaatan pupuk hayati Agri dan Glio terhadap hasil kedelai pada penelitian ini sama dengan hasil penelitian penggunaan produk pupuk hayati lainnya. Muzaiyanah et al.,(2015) melaporkan penelitian penggunaan pupuk hayati Santap NM1 dan Santap NM2 pada budidaya kedelai mampu meningkatkan jumlah polong isi per tanaman dan hasil kedelai. Sucahyono dan Harsono (2015) melaporkan hasil penelitian penggunaan pupuk hayati Probio pada budidaya kedelai mampu meningkatkan hasil kedelai. Selanjutnya penggunaan pupuk hayati dapat meningkatkan 
hasil kedelai rata-rata $0,5 \mathrm{t} \mathrm{ha}^{-1}$ (Saraswati, 2013; Purwarni dan Pratiwi (2015).

\section{KESIMPULAN}

Pemberian kombinasi pupuk hayati Agrimeth $200 \mathrm{~g}$ ha 1 + Gliocompost $20 \mathrm{~kg} \mathrm{ha}^{-1}$ + pupuk rekomendasi pada budidaya kedelai di lahan sawah di Pandeglang, Banten mampu memberikan pertumbuhan tinggi tanaman, jumlah daun, jumlah bintil akar dan jumlah bunga terbaik, demikian pula pada hasil kedelai lebih baik sebesar 2,01 $\mathrm{tha}^{-1}$.

\section{DAFTAR PUSTAKA}

Balai Penelitian Tanaman Hias. 2015. Pupuk Hayati Gliocompost. Balai Penelitian Tanaman Hias, Bogor.

Balai Penelitian Tanah. 2015. Pupuk Hayati Agrimeth. Balai Penelitian Tanah, Bogor.

Balai Penelitian Tanaman Aneka Kacang dan Umbi. 2013. Deskripsi kedelai Varietas Gema. Balai Penelitian Tanaman Aneka Kacang dan Umbi, Malang. 25 hal.

Hakim, L. 2012. Komponen hasil dan karakter morfologi penentu hasil kedelai. Jurnal Penelitian Pertanian Tanaman Pangan. 31(3):175-179.

Harsono, A. Subandi, dan Suryantini. 2012. Formulasi pupuk hayati dan organik untuk meningkatkan produktivitas aneka kacang 20\%, ubi $40 \%$ menghemat pupuk kimia 50\%. Laporan Hasil Penelitian Tahun 2010. Balitkabi. 53 halaman.

Harsono, A., Subandi, Hamastini, D. Santosa, dan A. Sariya. 2013. Kajian keefektifan pupuk hayati pada kedelai di lahan kering masam. Laporan Kerjasama Badan Penelitian dan Pengembangan Pertanian dengan Komite Inovasi Nasional. 22 halaman.

Manshuri, A. G. 2010. Pemupukan N, P dan K pada kedelai sesuai kebutuhan tanaman dan daya dukung lahan. J Penelitian Pertanian Tanaman pangan. 29(3):171-179.

Muzaiyanah, S., A.Kristiono; Subandi. 2015. Pengaruh pupuk organik kaya hara Santap NM1 dan Santap NM2 terhadap pertumbuhan dan hasil kedelai pada tanah vertisol. Buletin Palawija. 13(1):74-82.

Purwani, J dan E. Pratiwi. 2015. Pengaruh pupuk hayati terhadap pertumbuhan dan hasil kedelai pada ultisols Kabupaten Serang di rumah kaca. hal 155-162. Dalam Rahmianna, A.A., Sholihin, N. Nugrahaeni (Eds.). Prosiding Peran Inovasi Teknologi Aneka Kacang dan Umbi dalam Mendukung Program Kedaulatan Pangan. Malang 19 Mei 2015.
Saraswati, R. 2000. Peranan pupuk hayati dalam peningkatan produktivitas pangan. hal 46-54. Dalam Suwarno, et al. (Eds.). Prosiding Tonggak Kemajuan Teknologi Produksi Tanaman Pangan: Paket dan komponen Teknologi Produksi Padi. Bogor, 22-24 November 1999.

Saraswati, R. 2013. Potensi penggunaan pupuk mikroba secara terpadu pada kedelai. hal. 375-381. Dalam Sumarno, Suyamto, A. Widjono, Hermanto, H. Kasim (Eds.). Kedelai Teknik Produksi dan Pengembangan. Badan Penelitian dan Pengembangan Pertanian, Pusat Penelitian dan Pengembangan Tanaman Pangan, Malang.

Sasli, I. 2013. Respon tanaman kedelai terhadap pupuk hayati mikoriza arbuskula hasil rekayasa spesifik gambut. Agrovigor. 6(1):73-80.

Soedarjo, M. 2013. Teknologi Rhizobium pada tanaman kedelai. hal. 345-374. Dalam Sumarno, Suyamto, A. Widjono, Hermanto, H. Kasim (Eds.). Kedelai Teknik Produksi dan Pengembangan. Badan Penelitian dan Pengembangan Pertanian, Pusat Penelitian dan Pengembangan Tanaman Pangan, Malang.

Sucahyono, D. dan A. Harsono. 2015. Keefektifan pupuk hayati di lahan non masam. hal 142-150. Dalam Rahmianna, A.A., Sholihin, N. Nugrahaeni (Eds.). Prosiding Peran Inovasi Teknologi Aneka Kacang dan Umbi dalam Mendukung Program Kedaulatan Pangan. Malang, 19 Mei 2015.

Suhartatik, E dan R. Sismiyati. 2000. Pemanfaatan pupuk organik dan agent hayati pada padi sawah. hal. 81-98. Dalam Suwarno, et al., (Eds.). Prosiding Tonggak Kemajuan Teknologi Produksi Tanaman Pangan: Paket dan komponen Teknologi Produksi Padi. Bogor, 22-24 November 1999.

Sutoro, Dewi, N dan Setyowati, M. 2008. Hubungan sifat morfologis tanaman dengan hasil kedelai. J Penelitian Pertanian Tanaman Pangan. 127(3):185-1190.

Sumarsono dan Zuraida. 2006. Hubungan korelatif dan kausatif antara komponen hasil dengan hasil biji kedelai. J Penelitian Pertanian Tanaman Pangan. 25(1):38-43 